\title{
TINJAUAN STANDART KESTABILAN TOWER NG STANDAR 30 METER TERHADAP BEBAN GEMPA DINAMIS DENGAN BERBAGAI SITUS KELAS \\ TANAH SESUAI SNI 1726-2012 \\ ( Study kasus Tower NG Standart 30 m, Kabupaten Jember )
}

Sigid Bayu Sudarmaji ${ }^{1}$, Muhtar ${ }^{2}$, Pujo Priyono ${ }^{3}$

Program Studi Teknik Sipil, Fakultas Teknik, Universitas Muhammadiyah Jember

Jl. Karimata 49, Jember 68121, Indonesia

Email: sigid.bayu@gmail.com

\begin{abstract}
The development of world telecommunications is growing very rapidly occur today, requires the telecommunications provider to provide a means of expanding the reach of mobile phone signal and internet signal in the form of $2 G, 3 G$ and $4 G$. With it the necessary means of supporting specialized tower BTS (Base Transceiver Station) to carry the antenna at a certain height.

In planning the establishment of the BTS tower. The load effect in the form of self weight live load and wind load. But necessary review of the value of the Twist, Sway, and Displacement due to earthquake loads that occur with a variety of site classes of the soil in the form of rock soil, hard soil, medium soil and soft soil in accordance with SNI 1726-2012.
\end{abstract}

Keywords : BTS Tower, value of Twist, Sway, and Displacement, SNI 1726-2012 


\section{PENDAHULUAN}

Perkembangan dunia telekomunikasi yang berkembang sangat pesat terjadi dewasa ini, menuntut para provider telekomunikasi untuk berlomba-lomba merebut hati banyak para konsumen. Salah satu wujud untuk merebut hati para konsumen adalah dengan perluasan jangkauan sinyal telepon seluler dan sinyal internet dalam bentuk $2 \mathrm{G}, 3 \mathrm{G}$ dan $4 \mathrm{G}$. Keberadaan sinyal telepon dan sinyal internet yang kuat dikarenakan adanya antenna pemancar sinyal ataupun antenna penerima sinyal diwilayah jangkauan area tersebut. Antenna Ini akan berfungsi dengan jangkauan yang sesuai dengan kapasitasnya, apabila antenna tersebut terletak diketinggian tertentu. Untuk mensiasati keberadaan antenna yang harus dipasang dalam ketinggian tertentu, mengharuskan pembangunan tower BTS (Base Transceiver Station). BTS adalah bagian dari network element GSM yang berhubungan langsung dengan Mobile Station (MS). Beban yang mempengaruhi Tower BTS adalah beban tower itu sendiri, beban hidup dan beban angin karena pengaruh perbandingan ketinggian dan lebar struktur yang sangat besar. Namun pada pengaplikasian di lapangan dimana penempatan tower BTS yang dilakukan di seluruh wilayah Indonesia dengan situs kelas tanan yang benareka ragam maka perlunya di analisa akibat beban gempa yang terjadi. Sehingga kita bisa mengganalisa berapa besar nilai Displacement yang terjadi saat gempa agar tidak melebihi nilai yang di ijinkan. Sehingga dapat ditentukan rumusan masalah Bagaimana pengaruh beban gempa terhadap nilai Twist, Sway, dan Displacement yang terjadi pada struktur tower BTS, Bagaimana pengaruh situs kelas tanah yang beraneka ragam terhadap nilai Twist, Sway, dan Displacement yang terjadi pada struktur tower BTS saat terjadi gempa dan Berapa besar pengaruh Displacement pada arah $x, y, z$ yang terjadi akibat beban gempa.

\section{METODE PENELITIAN Data Umum}

Perencanaan struktur baja dan konstruksi tower, antara lain :

1. EIA-222F "Structural Standards for Steel Antenna Tower and Antenna Supporting Structure ."

2. American Institute of Steel Construction (AISC).

3. American Society For Testing And Materials (ASTM).

4. The fabrication and materials of the tower will be according to the relevant Indonesian Standard and/or Japanese Industrial Standard.

5. American Concrete Institute (ACI 318RM-99)

6. SNI 1726-2012 Tata Cara Perencanaan Struktur Bangunan Gedung Dan Non Gedung

7. Aplikasi Sap 2000 V.14, MS tover V6.02

\section{Perancangan Struktur Atas}

Data-data yang diperlukan, berupa :

1. Tinggi Menara : 30.00 meter

2. Material

a. Angle \& Plate Fy 245, Fu 400

b. Bolt Fy 600, Fu 800

c. Anchor Fy 245, Fu 400

3. Elevasi Tower : 0.0 meter Above Ground Level

4. Kecepatan Angin Maksimum (V). Dalam desain struktur menara, angin dasar (mil tercepat) kecepatan diambil: $V=120 \mathrm{~km} / \mathrm{jam}$ $=33.33 \mathrm{~m} /$ detik.

5. Kecepatan Angin Operasional (V) Untuk analisis Pemindahan, kecepatan angin dasar (mil tercepat) diambil: $V=84 \mathrm{~km} / \mathrm{jam}$ $=23.33 \mathrm{~m} /$ detik .

Twist / puntiran $\quad=0.5^{\circ}$

Sway/goyangan $\quad=0.5^{\circ}$

Displacement $/$ Perpindahan $=$ H/200 
6. Beban Antenna

a. Satu Ring Mounting Antena Disk Diameter (-) pada elevasi $\pm 28 \mathrm{~m}$.

b. Sembilan Sectoral Antena Disk Diameter 2.5 m pada elevasi \pm $28 \mathrm{~m}$.

c. Sembilan Antenna RRU pada elevasi $+25.0 \mathrm{~m}$.

d. Enam Antenna Microwave

e. pada elevasi $\pm 24.0 \mathrm{~m}$.

\section{Flowchart Tahap Perencanaan}

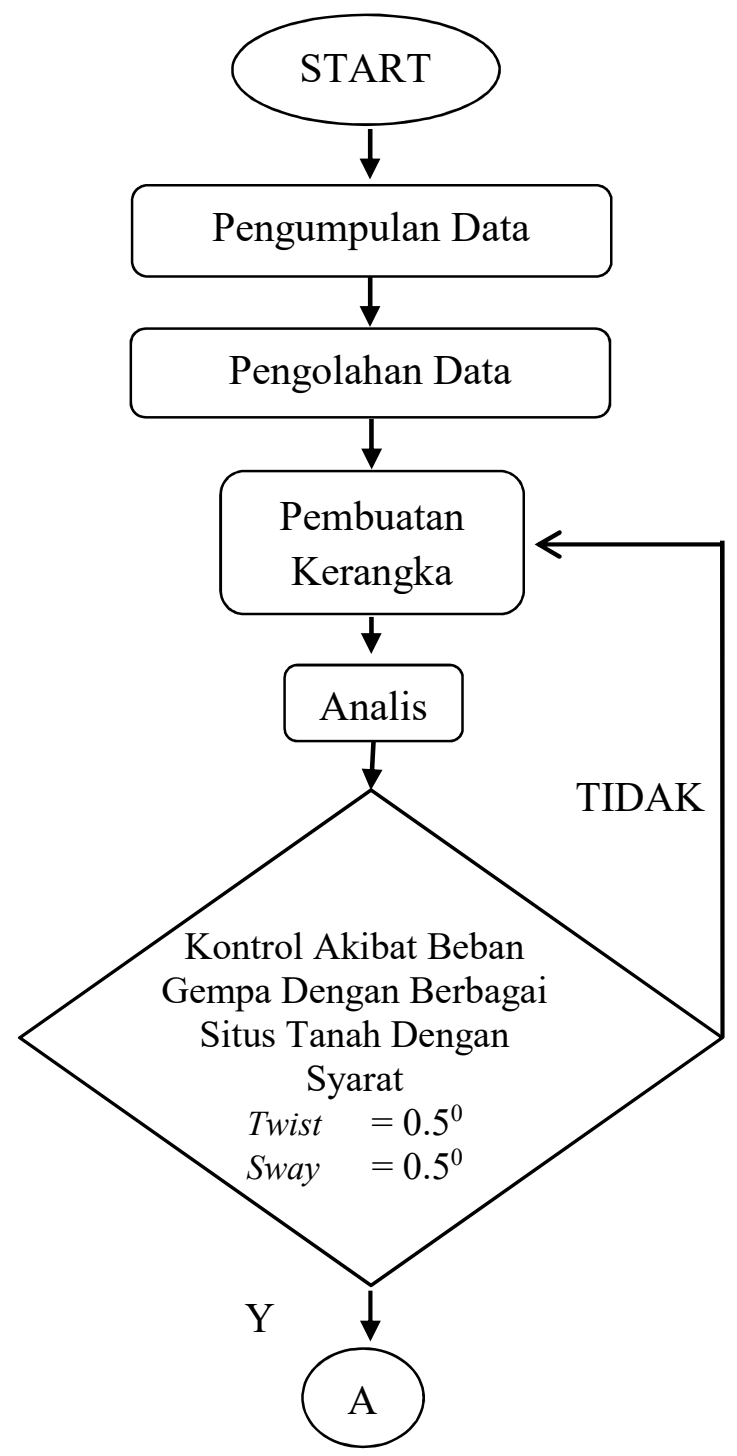

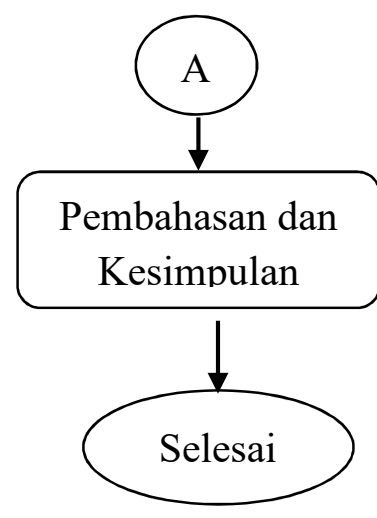

\section{HASIL DAN PEMBAHASAN Data Perencanaan}

1. Tinggi Menara : 30.00 meter

2. Material

a. Angle \& Plate Fy 245, Fu 400

b. Bolt Fy 600, Fu 800

c. Anchor Fy 245, Fu 400

3. Elevasi Tower : 0.0 meter Above Ground Level

4. Dimensi Profil Menggunakan Baja Siku Sama Kaki

Tabel 1 Profil Baja Siku Sama Kaki

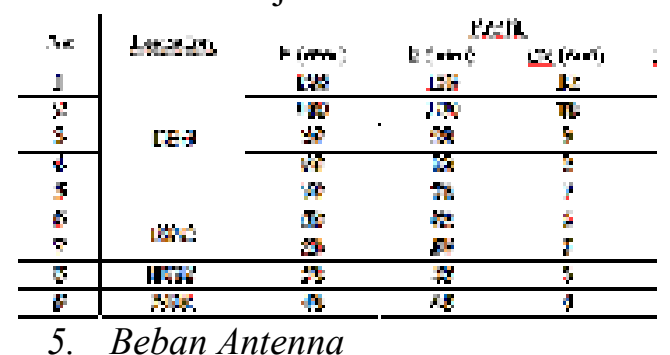

a. Satu Ring Mounting Antena Disk Diameter (-), berat $2.5 \mathrm{~kg}$ pada elevasi $\pm 28 \mathrm{~m}$.

b. Sembilan Sectoral Antena Disk Diameter $2.5 \mathrm{~m}$, berat $40 \mathrm{~kg}$ pada elevasi $\pm 28 \mathrm{~m}$.

c. Sembilan Antenna RRU Disk Diameter(-), berat $25 \mathrm{~kg}$ pada elevasi $\pm 25.0 \mathrm{~m}$.

d. Enam Antenna Microwave Disk Diameter (0.6), berat $30 \mathrm{~kg}$ pada elevasi. $\pm 24.0 \mathrm{~m}$. 


\section{Pemodelan Struktur}

1. Penempatan profil profil baja siku sama kaki pada struktur tower.

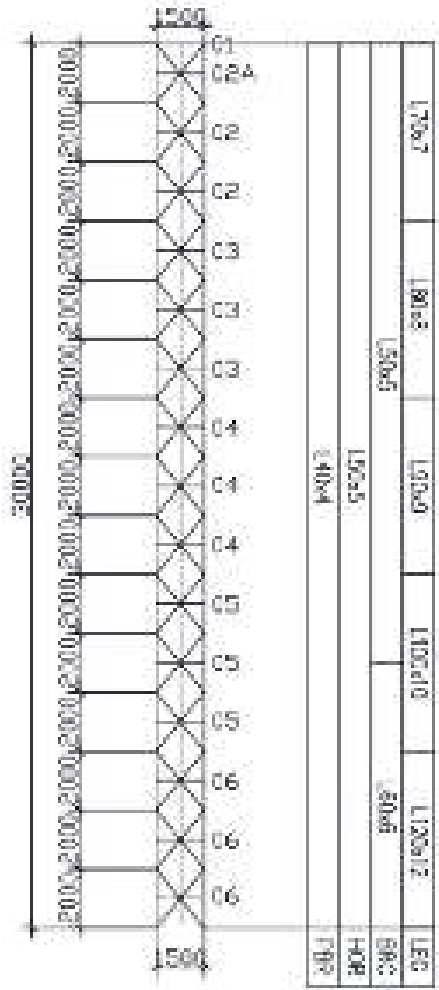

Gambar 1 Pemodelan Struktur Tower

2. Pemodelan struktur menggunakan aplikasi SAP 2000 V.14

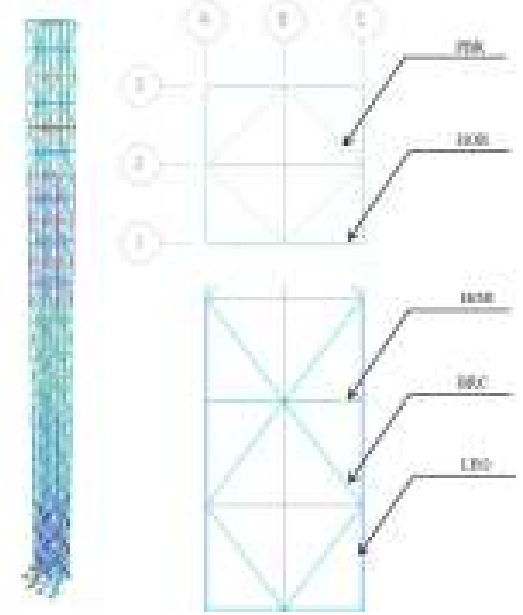

Gambar 2 Pemodelan Struktur Tower Pada Sap 2000V.14
Penempatan Beban Antena

Tabel 2 Penempatan Beban Antena

\begin{tabular}{|c|c|c|c|c|}
\hline $\mathrm{K}=$ & $I \mathbf{k}=\mathrm{L}$ & Dit & desret & Ke. \\
\hline & & 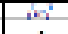 & $9 \Omega^{\prime}$ & \\
\hline$\frac{1}{4}$ & $\frac{x i n}{11}$ & घं & सं & Iregrista \\
\hline & 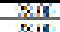 & 29 & $n$ & Snill \\
\hline 5 & $\sin$ & 3 & !y & sament \\
\hline & $\sin$ & 3is & 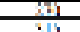 & $\operatorname{sen}$ \\
\hline & sid & ?y & 光 & incout \\
\hline$y$ & $\frac{\sin }{x / 10}$ & $\frac{31}{29}$ & $\frac{35}{111}$ & $\frac{\operatorname{sen} 20}{\sin 21}$ \\
\hline & -20 & & 4 & the \\
\hline$\frac{29}{14}$ & $\frac{8 \pi}{2 \pi}$ & & 111 & $\frac{981}{8 K 1}$ \\
\hline 7 & स्थल & - & $m$ & Hint \\
\hline & 7 & & +4 & 4 \\
\hline it. & ;.e & & 1 & in \\
\hline+5 & 50 & & तो & $\frac{9}{36}$ \\
\hline 32 & N.6 & : & 1 & Anand \\
\hline & m & In & ति & 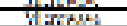 \\
\hline 3 & Mig & in & & Hanch \\
\hline 4 & (1) & tin & +13 & 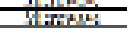 \\
\hline
\end{tabular}

\section{Pembebanan Antena}

1. Beban mati berupa berat struktur tower.

2. Beban hidup berupa beban pekerja pada saat pengerjaan sebesar $100 \mathrm{~kg}$.

3. Beban mati tambahan berupa beban antenna :

a. Ring Mounting Antena Disk Diameter (-), berat $2.5 \mathrm{~kg}$.

b. Sectoral Antena Disk Diameter $2.5 \mathrm{~m}$, berat $40 \mathrm{~kg}$.

c. Antenna RRU Disk Diameter $(-)$, berat $25 \mathrm{~kg}$.

d. Antenna Microwave Disk Diameter (0.6), berat $30 \mathrm{~kg}$.

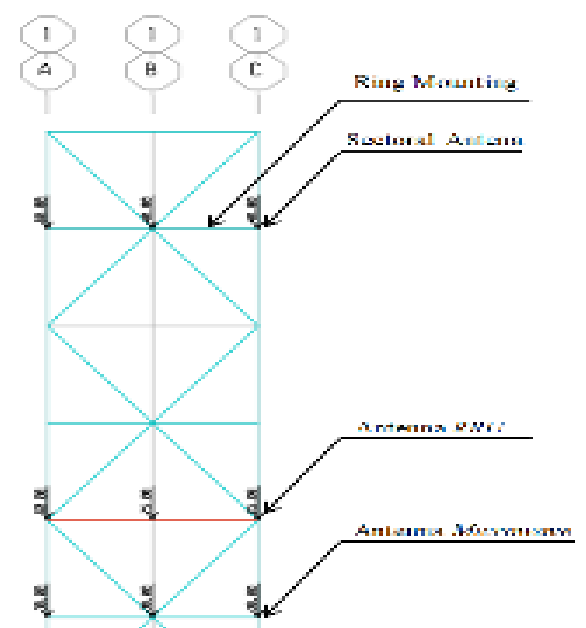

Gambar 3 Pembebanan Beban Antena 
4. Beban Angin

a. Kecepatan Angin Maksimum (V)Dalam desain struktur menara, angin dasar (mil tercepat) kecepatan diambil : $V=120 \mathrm{~km} / \mathrm{jam}=33.33 \mathrm{~m} / \mathrm{sec}$

Tekanan angina $p=\frac{V^{2}}{16}$

$V=33.33 \mathrm{~m} / \mathrm{s}$

$$
\begin{aligned}
& P=\frac{33.33^{2}}{16} \mathrm{~kg} / \mathrm{m}^{2}=69.3 \quad \mathrm{~kg} / \mathrm{m}^{2} \\
& \text { Jarak rangka }=1.5 \mathrm{~m} \\
& \text { Sudut }=0^{0}
\end{aligned}
$$

b. Kecepatan Angin Operasional

(V).Untuk analisis Pemindahan,

kecepatan angin dasar (mil tercepat)diambil : $\quad V=84 \mathrm{~km} / \mathrm{jam}$ $=23.33 \mathrm{~m} /$ detik Tekanan angin $p=$ $\frac{V^{2}}{16}$

$V=23.33 \mathrm{~m} / \mathrm{s} P=\frac{23.33^{2}}{16} \mathrm{~kg} / \mathrm{m}^{2}$

$=34 \mathrm{~kg} / \mathrm{m}^{2}$

Jarak rangka $\quad=1.5$

$$
\text { mSudut }=0^{\circ}
$$

Tekanan angin $(w)=34 \quad \mathrm{~kg} / \mathrm{m}^{2}$

Koefisien angin tekan untuk

rangka (cl) $=1.6$

Maka $W 1=$ c1.w.0,3

$=1.6 \times 34 \times 0.3=16.3 \mathrm{~kg} / \mathrm{m}$

Imput beban angin pada arah

$0^{0}, 45^{0}, 90^{0}, 135^{0}, 180^{0}, 225^{0}, 270^{0}, 315^{0}$
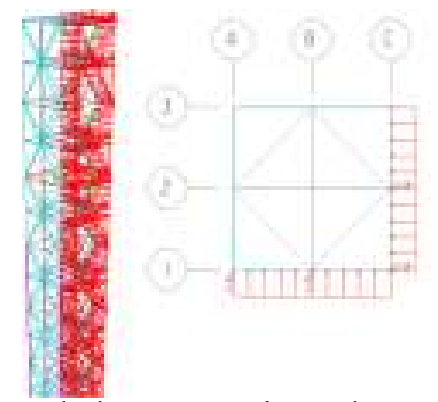

Gambar 4 Pembebanan Angin Pada Sudut $315^{\circ}$.

\section{Beban Gempa}

Beban Gempa menggunakan Nilai Spektra Gempa pada wilayah Kabupaten Jember dapat diketahui denga menggunakan web site http://puskim.pu.go.id/Aplikasi/desain spektra indonesia 2011/ dengan Koordinat Kabupaten Jember $=8^{\circ} 10^{\prime} 8^{\prime \prime} S 113^{\circ} 42^{\prime} 8^{\prime \prime} E$. . Hasil Analisa Desain Spektra sebagai berikut.

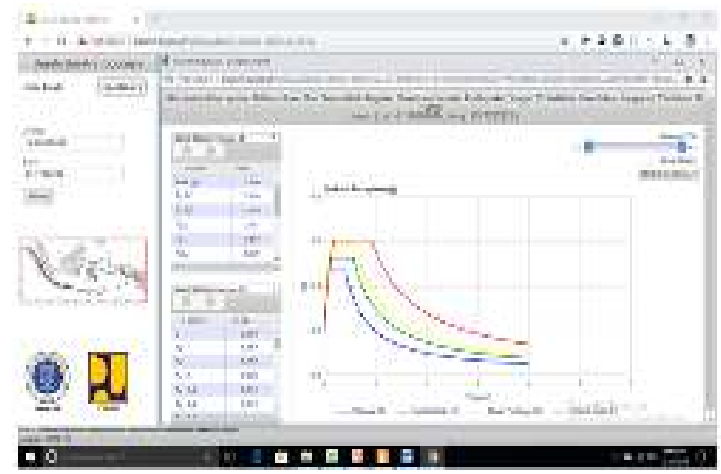

Gambar 5 Desain Spektra Kabupaten Jember

Dari hasil analisa diatas dapat diketahui berbagai situs kelas tanah yang ada sebagai berikut.

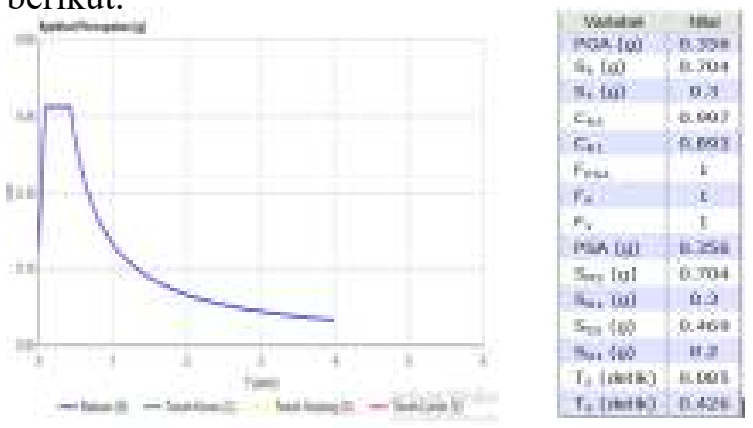

Gambar 6 Jenis Tanah : Batuan 


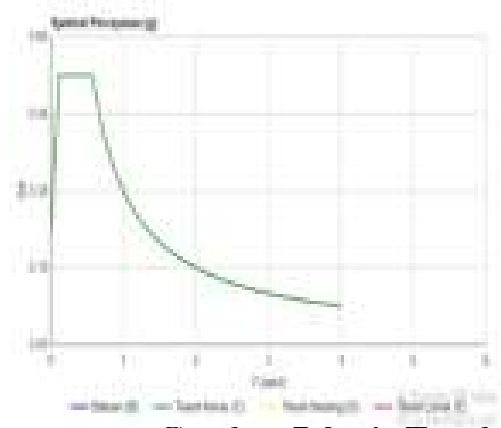

Gambar 7 Jenis Tanah : Keras

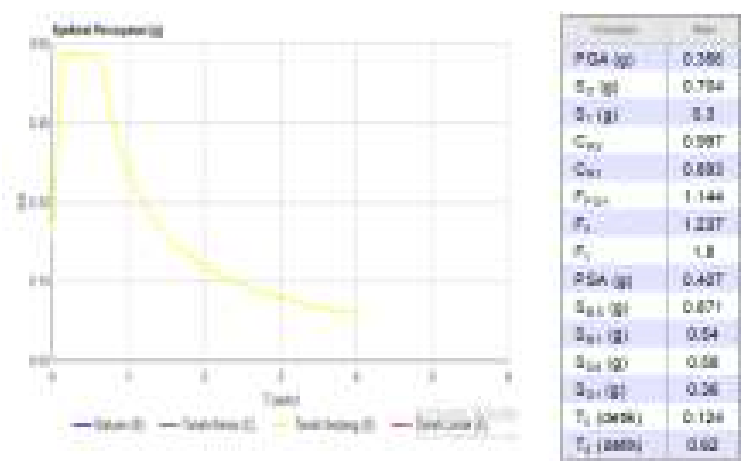

Gambar 8 Jenis Tanah : Sedang
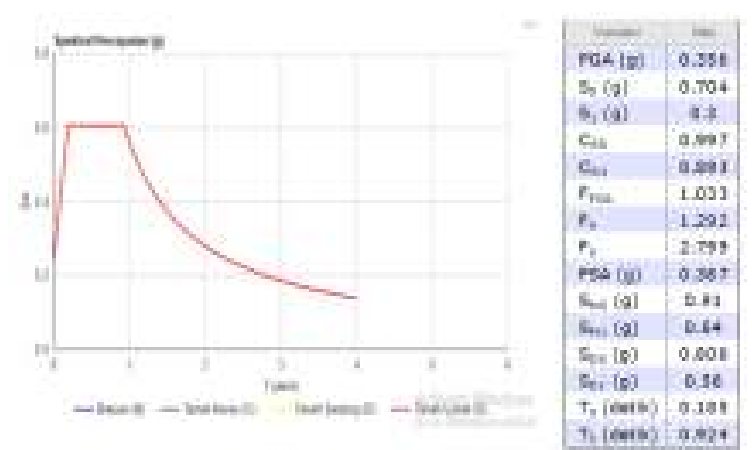

Gambar 9 Jenis Tanah : Lunak

\section{Kombinasi Pembebanan}

1. $1,4 \mathrm{D}$

2. $1,2 \mathrm{D}+1,6 \mathrm{~L}+0,5(\mathrm{Lr}$ atau $\mathrm{R})$

3. $1,2 \mathrm{D}+1,6(\mathrm{Lr}$ atau $\mathrm{R})+(\mathrm{L}$ atau $0,5 \mathrm{~W})$

4. $1,2 \mathrm{D}+1,0 \mathrm{~W}+\mathrm{L}+0,5(\mathrm{Lr}$ atau $\mathrm{R})$

5. $1,2 \mathrm{D}+1,0 \mathrm{E}+\mathrm{L}$

a. 1,2D $+1,0 \mathrm{E}$ (Tanah batuan) $+\mathrm{L}$

b. 1,2D +1,0E (Tanah keras) $+\mathrm{L}$ c. 1,2D $+1,0 \mathrm{E}$ (Tanah sedang) $+\mathrm{L}$

d. 1,2D $+1,0 \mathrm{E}$ (Tanah lunak) $+\mathrm{L}$

6. $0,9 \mathrm{D}+1,0 \mathrm{~W}$

7. $0,9 \mathrm{D}+1,0 \mathrm{E}$

Dimana :

$\mathrm{D}=$ Pengaruh dari beban mati.

$\mathrm{L} \quad=$ Pengaruh beban hidup

$\mathrm{Lr}=$ Pengaruh beban hidup tambahan

$\mathrm{R}=$ Beban air hujan

$\mathrm{W}=$ Beban angina

$\mathrm{E}=$ Pengaruh beban gempa

\section{Hasil Analisa Struktur Menggunakan SAP} 2000 V.14

1. Hasil Analisa Twist yang terjadi pada tower

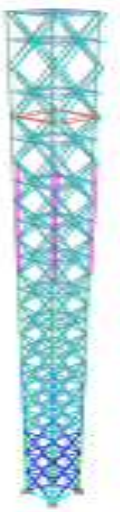

Gambar 10 Twist Yang Terjadi Pada Tower

Tabel 3 Twist Yang Terjadi Pada Jenis Tanah Batuan

\begin{tabular}{|c|c|c|c|c|c|c|c|c|}
\hline \multicolumn{9}{|c|}{ TABLE: Joint Displacements } \\
\hline Joint & OutputCase & R1 & R2 & R3 & R1 & R2 & R3 & Kontrol \\
\hline Text & Text & Radians & Radians & Radians & degree & degree & degree & $<0.5^{\circ}$ \\
\hline 1 & TANAH BATUAN & 0.000042 & 0.000194 & $4.558 \mathrm{E}-09$ & 0.0024 & 0.0111 & 0.0000003 & $0 \mathrm{k}$ \\
\hline 2 & TANAH BATUAN & 0.000042 & 0.000194 & 4.558E-09 & 0.0024 & 0.0111 & 0.0000003 & $0 \mathrm{k}$ \\
\hline 3 & TANAH BATUAN & 0.000042 & 0.000194 & $2.097 E-08$ & 0.0024 & 0.0111 & 0.0000012 & $0 \mathrm{k}$ \\
\hline 4 & TANAH BATUAN & 0.000042 & 0.000194 & $2.097 E-08$ & 0.0024 & 0.0111 & 0.0000012 & $0 \mathrm{k}$ \\
\hline 829 & TANAH BATUAN & 0.000042 & 0.000194 & $4.734 E-08$ & 0.0024 & 0.0111 & 0.0000027 & $0 \mathrm{k}$ \\
\hline 835 & TANAH BATUAN & 0.000042 & 0.000194 & $4.734 E-08$ & 0.0024 & 0.0111 & 0.0000027 & $0 \mathrm{k}$ \\
\hline 952 & TANAH BATUAN & 0.000042 & 0.000194 & $4.734 E-08$ & 0.0024 & 0.0111 & 0.0000027 & $0 \mathrm{k}$ \\
\hline 958 & TANAH BATUAN & 0.000042 & 0.000194 & $4.734 E-08$ & 0.0024 & 0.0111 & 0.0000027 & $0 \mathrm{k}$ \\
\hline
\end{tabular}


Tabel 4 Twist Yang Terjadi Pada Jenis Tanah

Keras

\begin{tabular}{|c|c|c|c|c|c|c|c|c|}
\hline \multicolumn{9}{|c|}{ TABLE: Joint Displacements } \\
\hline Joint & OutputCase & R1 & R2 & R3 & R1 & $\mathrm{R} 2$ & R3 & Kontrol \\
\hline Text & Text & Radians & Radians & Radians & degree & degree & degree & $<0.5^{\circ}$ \\
\hline 1 & TANAH KERAS & 0.000069 & 0.000227 & 7.13E-09 & 0.0040 & 0.0130 & 0.0000004 & $0 \mathrm{k}$ \\
\hline 2 & TANAH KERAS & 0.000069 & 0.000227 & $7.13 \mathrm{E}-09$ & 0.0040 & 0.0130 & 0.0000004 & $0 \mathrm{k}$ \\
\hline 3 & TANAH KERAS & 0.000069 & 0.000227 & $2.343 E-08$ & 0.0040 & 0.0130 & 0.0000013 & $0 \mathrm{k}$ \\
\hline 4 & TANAH KERAS & 0.000069 & 0.000227 & $2.343 E-08$ & 0.0040 & 0.0130 & 0.0000013 & $0 \mathrm{k}$ \\
\hline 829 & TANAH KERAS & 0.000069 & 0.000227 & $5.414 \mathrm{E}-08$ & 0.0040 & 0.0130 & 0.0000031 & $0 \mathrm{k}$ \\
\hline 835 & TANAH KERAS & 0.000069 & 0.000227 & $5.414 \mathrm{E}-08$ & 0.0040 & 0.0130 & 0.0000031 & $0 \mathrm{k}$ \\
\hline 952 & TANAH KERAS & 0.000069 & 0.000227 & $5.414 \mathrm{E}-08$ & 0.0040 & 0.0130 & 0.0000031 & Ok \\
\hline 958 & TANAH KERAS & 0.000069 & 0.000227 & $5.414 E-08$ & 0.0040 & 0.0130 & 0.0000031 & Ok \\
\hline
\end{tabular}

Tabel 5 Twist Yang Terjadi Pada Jenis Tanah Sedang

\begin{tabular}{|c|c|c|c|c|c|c|c|c|}
\hline \multicolumn{9}{|c|}{ TABLE: Joint Displacements } \\
\hline Joint & OutputCase & R1 & R2 & R3 & R1 & R2 & R3 & Kontro \\
\hline Text & Text & Radians & Radians & Radians & degree & degree & degree & $<0.5^{\circ}$ \\
\hline 1 & TANAHSEDANG & 0.000076 & 0.000251 & 7.803E-09 & 0.0044 & 0.0144 & 0.0000004 & Ok \\
\hline 2 & TANAHSEDANG & 0.000076 & 0.000251 & 7.803E-09 & 0.0044 & 0.0144 & 0.0000004 & $0 \mathrm{k}$ \\
\hline 3 & TANAHSEDANG & 0.000076 & 0.000251 & $2.564 \mathrm{E}-08$ & 0.0044 & 0.0144 & 0.0000015 & $0 \mathrm{k}$ \\
\hline 4 & TANAHSEDANG & 0.000076 & 0.000251 & $2.564 \mathrm{E}-08$ & 0.0044 & 0.0144 & 0.0000015 & $0 \mathrm{k}$ \\
\hline 829 & TANAH SEDANG & 0.000076 & 0.000251 & $5.927 \mathrm{E}-08$ & 0.0044 & 0.0144 & 0.0000034 & $0 \mathrm{k}$ \\
\hline 835 & TANAHSEDANG & 0.000076 & 0.000251 & $5.927 \mathrm{E}-08$ & 0.0044 & 0.0144 & 0.0000034 & Ok \\
\hline 952 & TANAHSEDANG & 0.000076 & 0.000251 & $5.927 \mathrm{E}-08$ & 0.0044 & 0.0144 & 0.0000034 & Ok \\
\hline 958 & TANAHSEDANG & 0.000076 & 0.000251 & $5.927 \mathrm{E}-08$ & 0.0044 & 0.0144 & 0.0000034 & $0 \mathrm{k}$ \\
\hline
\end{tabular}

Tabel 6 Twist Yang Terjadi Pada Jenis Tanah Lunak

\begin{tabular}{|c|c|c|c|c|c|c|c|c|}
\hline \multicolumn{9}{|c|}{ TABLE: Joint Displacements } \\
\hline Joint & OutputCase & R1 & R2 & R3 & R1 & R2 & R3 & Kontro \\
\hline Text & Text & Radians & Radians & Radians & degree & degree & degree & $<0.5^{\circ}$ \\
\hline 1 & TANAH LUNAK & 0.00008 & 0.000262 & $7.87 E-09$ & 0.0046 & 0.0150 & 0.0000005 & $0 \mathrm{k}$ \\
\hline 2 & TANAH LUNAK & 0.00008 & 0.000262 & $7.87 \mathrm{E}-09$ & 0.0046 & 0.0150 & 0.0000005 & $0 \mathrm{k}$ \\
\hline 3 & TANAH LUNAK & 0.00008 & 0.000262 & $2.586 \mathrm{E}-08$ & 0.0046 & 0.0150 & 0.0000015 & $0 \mathrm{k}$ \\
\hline 4 & TANAH LUNAK & 0.00008 & 0.000262 & $2.586 \mathrm{E}-08$ & 0.0046 & 0.0150 & 0.0000015 & $0 \mathrm{k}$ \\
\hline 829 & TANAH LUNAK & 0.00008 & 0.000262 & $5.988 \mathrm{E}-08$ & 0.0046 & 0.0150 & 0.0000034 & $0 \mathrm{k}$ \\
\hline 835 & TANAH LUNAK & 0.00008 & 0.000262 & $5.988 \mathrm{E}-08$ & 0.0046 & 0.0150 & 0.0000034 & $0 \mathrm{k}$ \\
\hline 952 & TANAH LUNAK & 0.00008 & 0.000262 & $5.988 \mathrm{E}-08$ & 0.0046 & 0.0150 & 0.0000034 & $0 \mathrm{k}$ \\
\hline 958 & TANAH LUNAK & 0.00008 & 0.000262 & $5.988 \mathrm{E}-08$ & 0.0046 & 0.0150 & 0.0000034 & $0 \mathrm{k}$ \\
\hline
\end{tabular}

2. Hasil Analisa Sway yang terjadi pada tower

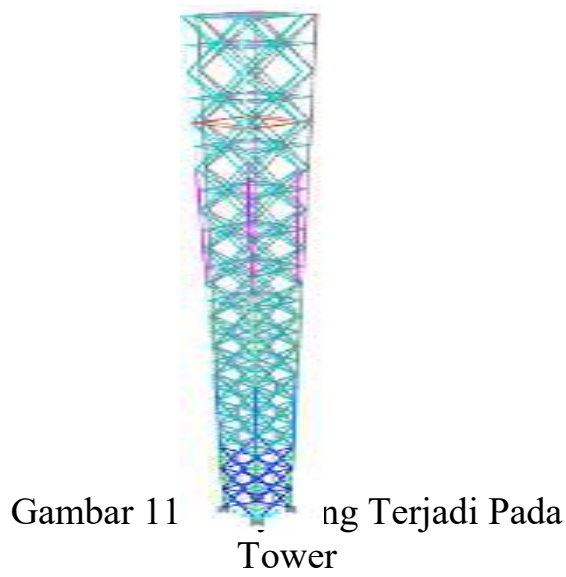

Tabel 7 Sway Yang Terjadi Pada Jenis Tanah Batu

\begin{tabular}{|c|c|c|c|c|c|c|c|c|}
\hline \multicolumn{9}{|c|}{ TABLE: Joint Velocities - Absolute } \\
\hline Joint & OutputCase & R1 & R2 & R3 & R1 & R2 & R3 & Kontrol \\
\hline Text & Text & $\mathrm{rad} / \mathrm{sec}$ & $\mathrm{rad} / \mathrm{sec}$ & $\mathrm{rad} / \mathrm{sec}$ & degree/sec & degree/sec & degree/sec & $<0.5^{\circ}$ \\
\hline 1 & TANAH BATUAN & 0.000668 & 0.003072 & $2.7722-07$ & 0.04 & 0.18 & 0.00 & $0 \mathrm{k}$ \\
\hline 2 & TANAH BATUAN & 0.000668 & 0.003072 & $2.772 E-07$ & 0.04 & 0.18 & 0.00 & $0 \mathrm{k}$ \\
\hline 3 & TANAH BATUAN & 0.000668 & 0.003072 & 0.000001275 & 0.04 & 0.18 & 0.00 & $0 \mathrm{k}$ \\
\hline 4 & TANAH BATUAN & 0.000668 & 0.003072 & 0.000001275 & 0.04 & 0.18 & 0.00 & $0 \mathrm{k}$ \\
\hline 829 & TANAH BATUAN & 0.00067 & 0.003082 & 0.00000277 & 0.04 & 0.18 & 0.00 & $0 \mathrm{k}$ \\
\hline 835 & TANAH BATUAN & 0.00067 & 0.003082 & 0.00000277 & 0.04 & 0.18 & 0.00 & $0 \mathrm{k}$ \\
\hline 952 & TANAH BATUAN & 0.00067 & 0.003082 & 0.00000277 & 0.04 & 0.18 & 0.00 & $0 \mathrm{k}$ \\
\hline 958 & TANAH BATUAN & 0.00067 & 0.003082 & 0.00000277 & 0.04 & 0.18 & 0.00 & $0 \mathrm{k}$ \\
\hline
\end{tabular}

Tabel 8 Sway Yang Terjadi Pada Jenis Tanah Keras

\begin{tabular}{|c|c|c|c|c|c|c|c|c|}
\hline \multicolumn{9}{|c|}{ TABLE: Joint Velocities - Absolute } \\
\hline Joint & Outputcase & R1 & R2 & R3 & R1 & R2 & R3 & Kontrol \\
\hline Text & Text & $\mathrm{rad} / \mathrm{sec}$ & $\mathrm{rad} / \mathrm{sec}$ & $\mathrm{rad} / \mathrm{sec}$ & degree/sec & degree/sec & degree/sec & $<0.5^{\circ}$ \\
\hline 1 & TANAH KERAS & 0.001069 & 0.003513 & $3.928 E-07$ & 0.06 & 0.20 & 0.00 & $0 \mathrm{k}$ \\
\hline 2 & TANAH KERAS & 0.001069 & 0.003513 & $3.928 E-07$ & 0.06 & 0.20 & 0.00 & $0 \mathrm{k}$ \\
\hline 3 & TANAH KERAS & 0.001069 & 0.003513 & 0.00000129 & 0.06 & 0.20 & 0.00 & $0 \mathrm{k}$ \\
\hline 4 & TANAH KERAS & 0.001069 & 0.003513 & 0.000001291 & 0.06 & 0.20 & 0.00 & $0 \mathrm{k}$ \\
\hline 829 & TANAH KERAS & 0.001072 & 0.003523 & 0.000002862 & 0.06 & 0.20 & 0.00 & $0 \mathrm{k}$ \\
\hline 835 & TANAH KERAS & 0.001072 & 0.003523 & 0.000002862 & 0.06 & 0.20 & 0.00 & $0 \mathrm{k}$ \\
\hline 952 & TANAH KERAS & 0.001072 & 0.003523 & 0.000002862 & 0.06 & 0.20 & 0.00 & $0 \mathrm{k}$ \\
\hline 958 & TANAH KERAS & 0.001072 & 0.003523 & 0.000002862 & 0.06 & 0.20 & 0.00 & $0 \mathrm{k}$ \\
\hline
\end{tabular}

Tabel 9 Sway Yang Terjadi Pada Jenis Tanah Sedang

\begin{tabular}{|c|c|c|c|c|c|c|c|c|}
\hline \multicolumn{9}{|c|}{ TABLE: Joint Velocities - Absolute } \\
\hline Joint & OutputCase & R1 & R2 & R3 & R1 & R2 & R3 & \multirow{2}{*}{$\begin{array}{l}\text { Kontrol } \\
<0.5^{\circ}\end{array}$} \\
\hline Text & Text & $\mathrm{rad} / \mathrm{sec}$ & $\mathrm{rad} / \mathrm{sec}$ & $\mathrm{rad} / \mathrm{sec}$ & degree/sec & degree/sec & degree/sec & \\
\hline 1 & TANAH SEDANG & 0.001175 & 0.003862 & 4.219E-07 & 0.07 & 0.22 & 0.00 & $0 \mathrm{k}$ \\
\hline 2 & TANAH SEDANG & 0.001175 & 0.003862 & 4.219E-07 & 0.07 & 0.22 & 0.00 & $0 \mathrm{k}$ \\
\hline 3 & TANAH SEDANG & 0.001175 & 0.003861 & 0.000001386 & 0.07 & 0.22 & 0.00 & $0 \mathrm{k}$ \\
\hline 4 & TANAH SEDANG & 0.001175 & 0.003861 & 0.000001386 & 0.07 & 0.22 & 0.00 & $0 \mathrm{k}$ \\
\hline 829 & TANAH SEDANG & 0.001179 & 0.003872 & 0.000003074 & 0.07 & 0.22 & 0.00 & $0 \mathrm{k}$ \\
\hline 835 & TANAH SEDANG & 0.001179 & 0.003872 & 0.000003074 & 0.07 & 0.22 & 0.00 & $0 \mathrm{k}$ \\
\hline 952 & TANAHSEDANG & 0.001179 & 0.003872 & 0.000003074 & 0.07 & 0.22 & 0.00 & $0 \mathrm{k}$ \\
\hline 958 & TANAH SEDANG & 0.001179 & 0.003872 & 0.000003074 & 0.07 & 0.22 & 0.00 & $0 \mathrm{k}$ \\
\hline
\end{tabular}

Tabel 10 Sway Yang Terjadi Pada Jenis Tanah Lunak

\begin{tabular}{|c|c|c|c|c|c|c|c|c|}
\hline \multicolumn{9}{|c|}{ TABLE: Joint Velocities - Absolute } \\
\hline Joint & OutputCase & R1 & R2 & R3 & R1 & R2 & R3 & Kontrol \\
\hline Text & Text & $\mathrm{rad} / \mathrm{sec}$ & $\mathrm{rad} / \mathrm{sec}$ & $\mathrm{rad} / \mathrm{sec}$ & degree/sec & degree/sec & degree/sec & $<0.5^{\circ}$ \\
\hline 1 & TANAH LUNAK & 0.001206 & 0.003962 & $3.914 \mathrm{E}-07$ & 0.07 & 0.23 & 0.00 & $0 \mathrm{k}$ \\
\hline 2 & TANAH LUNAK & 0.001206 & 0.003962 & $3.914 \mathrm{E}-07$ & 0.07 & 0.23 & 0.00 & $0 \mathrm{k}$ \\
\hline 3 & TANAH LUNAK & 0.001206 & 0.003961 & 0.000001286 & 0.07 & 0.23 & 0.00 & $0 \mathrm{k}$ \\
\hline 4 & TANAH LUNAK & 0.001206 & 0.003961 & 0.000001286 & 0.07 & 0.23 & 0.00 & $0 \mathrm{k}$ \\
\hline 829 & TANAH LUNAK & 0.001209 & 0.003972 & 0.000002848 & 0.07 & 0.23 & 0.00 & $0 \mathrm{k}$ \\
\hline 835 & TANAH LUNAK & 0.001209 & 0.003972 & 0.000002848 & 0.07 & 0.23 & 0.00 & $0 \mathrm{k}$ \\
\hline 952 & TANAH LUNAK & 0.001209 & 0.003972 & 0.000002848 & 0.07 & 0.23 & 0.00 & $0 \mathrm{k}$ \\
\hline 958 & TANAH LUNAK & 0.001209 & 0.003972 & 0.000002848 & 0.07 & 0.23 & 0.00 & $0 \mathrm{k}$ \\
\hline
\end{tabular}


3. Hasil analisa displacement yang terjadi pada tower

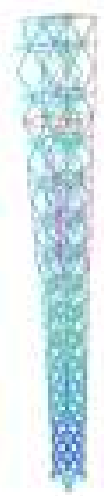

Gambar 12 Displacement Yang Terjadi Pada Tower

Tabel 11 Displacement Yang Terjadi Pada Jenis Tanah Batuan

\begin{tabular}{|c|c|c|c|c|c|c|c|}
\hline \multicolumn{8}{|c|}{ TABLE: Joint Displacements } \\
\hline Joint & OutputCase & CaseType & StepType & U1 & U2 & U3 & Kontrol \\
\hline Text & Text & Text & Text & $\mathrm{mm}$ & $\mathrm{mm}$ & $\mathrm{mm}$ & $\mathrm{H} / 200$ \\
\hline 1 & TANAH BATUAN & LinRespSpec & Max & 3.919099 & 0.851969 & 0.145126 & OK \\
\hline 2 & TANAH BATUAN & LinRespSpec & Max & 3.919099 & 0.851969 & 0.145126 & OK \\
\hline 3 & TANAH BATUAN & LinRespSpec & Max & 3.919058 & 0.851978 & 0.031549 & OK \\
\hline 4 & TANAH BATUAN & LinRespSpec & Max & 3.919058 & 0.851978 & 0.031549 & OK \\
\hline 829 & TANAH BATUAN & LinRespSpec & Max & 3.91903 & 0.851963 & 0.148499 & OK \\
\hline 835 & TANAH BATUAN & LinRespSpec & Max & 3.91903 & 0.851963 & 0.148499 & OK \\
\hline 952 & TANAH BATUAN & LinRespSpec & Max & 3.91903 & 0.851963 & 0.148499 & OK \\
\hline 958 & TANAH BATUAN & LinRespSpec & Max & 3.91903 & 0.851963 & 0.148499 & OK \\
\hline
\end{tabular}

Tabel 12 Displacement Yang Terjadi Pada Jenis Tanah Keras

\begin{tabular}{|c|c|c|c|c|c|c|c|}
\hline \multicolumn{8}{|c|}{ TABLE: Joint Displacements } \\
\hline Joint & OutputCase & CaseType & StepType & U1 & U2 & U3 & Kontrol \\
\hline Text & Text & Text & Text & $\mathrm{mm}$ & $\mathrm{mm}$ & $\mathrm{mm}$ & $H / 200$ \\
\hline 1 & TANAH KERAS & LinRespSpec & Max & 4.601747 & 1.400517 & 0.170215 & OK \\
\hline 2 & TANAH KERAS & LinRespSpec & Max & 4.601747 & 1.400517 & 0.170215 & OK \\
\hline 3 & TANAH KERAS & LinRespSpec & $\operatorname{Max}$ & 4.601698 & 1.400532 & 0.051805 & OK \\
\hline 4 & TANAH KERAS & LinRespSpec & $\operatorname{Max}$ & 4.601698 & 1.400532 & 0.051805 & OK \\
\hline 829 & TANAH KERAS & LinRespSpec & $\operatorname{Max}$ & 4.601666 & 1.400507 & 0.177905 & $\mathrm{OK}$ \\
\hline 835 & TANAH KERAS & LinRespSpec & Max & 4.601666 & 1.400507 & 0.177905 & $\mathrm{OK}$ \\
\hline 952 & TANAH KERAS & LinRespSpec & $\operatorname{Max}$ & 4.601666 & 1.400507 & 0.177905 & OK \\
\hline 958 & TANAH KERAS & LinRespSpec & $\operatorname{Max}$ & 4.601666 & 1.400507 & 0.177905 & $\mathrm{OK}$ \\
\hline
\end{tabular}

Tabel 13 Displacement Yang Terjadi Pada Jenis Tanah Sedang

\begin{tabular}{|c|c|c|c|c|c|c|c|}
\hline \multicolumn{8}{|c|}{ TABLE: Joint Displacements } \\
\hline Joint & OutputCase & CaseType & StepType & U1 & U2 & U3 & Kontrol \\
\hline Text & Text & Text & Text & $\mathrm{mm}$ & $\mathrm{mm}$ & $\mathrm{mm}$ & $\mathrm{H} / 200$ \\
\hline 1 & TANAH SEDANG & LinRespSpec & Max & 5.083739 & 1.547209 & 0.188005 & OK \\
\hline 2 & TANAH SEDANG & LinRespSpec & Max & 5.083739 & 1.547209 & 0.188005 & OK \\
\hline 3 & TANAH SEDANG & LinRespSpec & Max & 5.083686 & 1.547225 & 0.057219 & OK \\
\hline 4 & TANAH SEDANG & LinRespSpec & Max & 5.083686 & 1.547225 & 0.057219 & OK \\
\hline 829 & TANAH SEDANG & LinRespSpec & Max & 5.08365 & 1.547198 & 0.196499 & OK \\
\hline 835 & TANAH SEDANG & LinRespSpec & Max & 5.08365 & 1.547198 & 0.196499 & OK \\
\hline 952 & TANAH SEDANG & LinRespSpec & $\operatorname{Max}$ & 5.08365 & 1.547198 & 0.196499 & OK \\
\hline 958 & TANAH SEDANG & LinRespSpec & Max & 5.08365 & 1.547198 & 0.196499 & OK \\
\hline
\end{tabular}

Tabel 14 Displacement Yang Terjadi Pada Jenis Tanah Lunak

\begin{tabular}{|l|l|c|c|c|c|c|c|} 
TABLE: Joint Displacements & \\
\hline Joint & OutputCase & CaseType & StepType & U1 & U2 & U3 & Kontrol \\
\hline Text & Text & Text & Text & $\mathrm{mm}$ & $\mathrm{mm}$ & $\mathrm{mm}$ & $\mathrm{H} / 200$ \\
\hline 1 & TANAH LUNAK & LinRespSpec Max & 5.311284 & 1.616461 & 0.196277 & OK \\
\hline 2 & TANAH LUNAK & LinRespSpec Max & 5.311284 & 1.616461 & 0.196277 & OK \\
\hline 3 & TANAH LUNAK & LinRespSpec Max & 5.311228 & 1.616478 & 0.059737 & OK \\
\hline 4 & TANAH LUNAK & LinRespSpec Max & 5.311228 & 1.616478 & 0.059737 & OK \\
\hline 829 & TANAH LUNAK & LinRespSpec Max & 5.311191 & 1.61645 & 0.205145 & OK \\
\hline 835 & TANAH LUNAK & LinRespSpec Max & 5.311191 & 1.61645 & 0.205145 & OK \\
\hline 952 & TANAH LUNAK & LinRespSpec Max & 5.311191 & 1.61645 & 0.205145 & OK \\
\hline 958 & TANAH LUNAK & LinRespSpec Max & 5.311191 & 1.61645 & 0.205145 & OK \\
\hline
\end{tabular}

4. Hasil analisa Joint Reaction Pada Tower

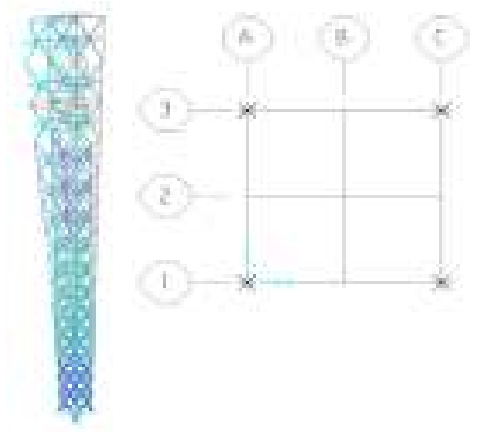

Gambar 13 Titik Joint Reaction Pada Tower

Tabel 15 Nilai Joint Reaction Pada Jenis Tanah Batuan

TABLE: Joint Reactions
\begin{tabular}{|c|c|c|c|c|c|c|c|}
\hline Joint & OutputCase & F1 & F2 & F3 & M1 & M2 & M3 \\
\hline Text & Text & N & N & N & N-mm & N-mm & N-mm \\
\hline 762 & TANAHBATUAN & 25537.18 & 38141.21 & 525264.61 & 23333374.22 & 101017001.2 & 2585403.7 \\
\hline 765 & TANAHBATUAN & 25537.18 & 38141.21 & 525264.61 & 23333974.31 & 101017001.1 & 2585403.7 \\
\hline 885 & TANAHBATUAN & 25537.18 & 38141.21 & 525264.61 & 23333374.24 & 101017001.2 & 2585403.7 \\
\hline 888 & TANAHBATUAN & 25537.18 & 38141.21 & 525264.61 & 23333977.28 & 101017001.1 & 2585403.7 \\
\hline
\end{tabular}


Tabel 16 Nilai Joint Reaction Pada Jenis Tanah Keras

\begin{tabular}{|c|c|c|c|c|c|c|c|}
\hline \multicolumn{8}{|c|}{ TABLE: Joint Reactions } \\
\hline Joint & OutputCase & F1 & F2 & F3 & M1 & M2 & M3 \\
\hline Text & Text & N & N & N & N-mm & $\mathrm{N}-\mathrm{mm}$ & N-mm \\
\hline 762 & TANAH KERAS & 30754.63 & 45050.37 & 628425.3 & 37066191.18 & 117961974.6 & 3075998 \\
\hline 765 & TANAHKERAS & 30754.63 & 45050.37 & 628425.3 & 37066191.26 & 117961974.6 & 3075998 \\
\hline 885 & TANAH KERAS & 30754.63 & 45050.37 & 628425.3 & 37066191.2 & 117961974.7 & 3075998 \\
\hline 888 & TANAHKERAS & 30754.63 & 45050.37 & 628425.3 & 37066191.23 & 117961974.6 & 3075998 \\
\hline
\end{tabular}

Tabel 17 Nilai Joint Reaction Pada Jenis Tanah Sedang

\begin{tabular}{|c|c|c|c|c|c|c|c|}
\hline TABLE: Joint Reactions \\
\hline Joint & OutputCase & F1 & F2 & F3 & M1 & M2 & M3 \\
\hline Text & Text & N & N & N & N-mm & N-mm & N-mm \\
\hline 762 & TANAHSEDANG & 33835.36 & 49740 & 693927.07 & 40907409.55 & 130180313.5 & 3393090.6 \\
\hline 765 & TANAHSEDANG & 33835.36 & 49740.01 & 693927.07 & 40907409.64 & 130180313.4 & 3393090.6 \\
\hline 885 & TANAHSEDANG & 33835.36 & 49740 & 693927.07 & 40907409.57 & 130180313.5 & 3393090.6 \\
\hline 888 & TANAHSEDANG & 33835.36 & 49740.01 & 693927.07 & 40907409.61 & 130180313.4 & 3393090.6 \\
\hline
\end{tabular}

Tabel 18 Nilai Joint Reaction Pada Jenis Tanah Lunak

\begin{tabular}{|c|c|c|c|c|c|c|c|}
\hline \\
\hline \multicolumn{8}{|c|}{$\begin{array}{l}\text { IAbLE: Joint Keactions } \\
\text { Joint }\end{array}$} \\
\hline Text & Text & $\mathrm{N}$ & $\mathrm{N}$ & $\mathrm{N}$ & $\mathrm{N}-\mathrm{mm}$ & $\mathrm{N}-\mathrm{mm}$ & $\mathrm{N}-\mathrm{mm}$ \\
\hline 762 & TANAH LUNAK & 34823.87 & 51858.75 & 723798.83 & 42585646.27 & 135497841.3 & 3526036.7 \\
\hline 765 & TANAH LUNAK & 34823.87 & 51858.75 & 723798.83 & 42585646.37 & 135497841.2 & 3526036.7 \\
\hline 885 & TANAH LUNAK & 34823.87 & 51858.75 & 723798.83 & 42585646.3 & 135497841.3 & 3526036.7 \\
\hline 888 & TANAH LUNAK & 34823.87 & 51858.75 & 723798.83 & 42585646.34 & 135497841.2 & 3526036.7 \\
\hline
\end{tabular}

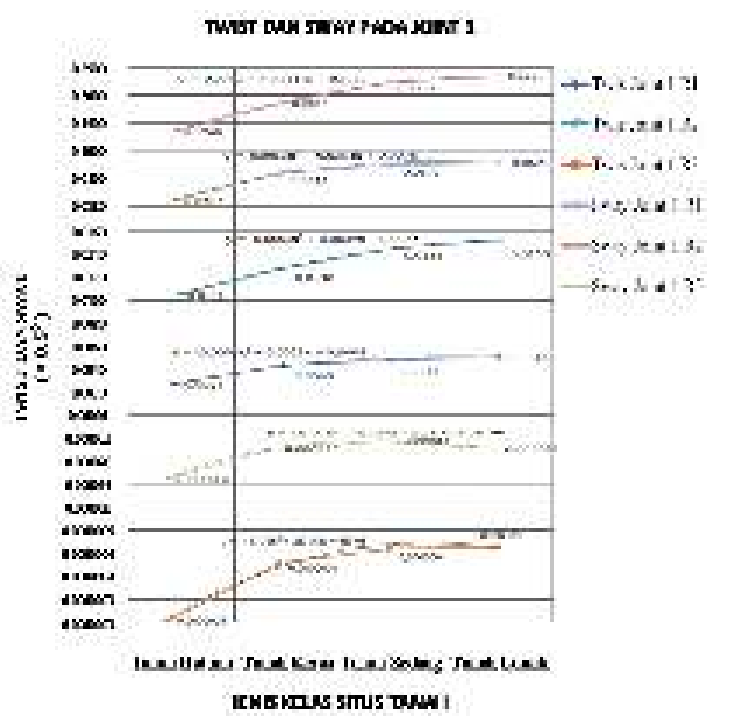

Gambar 14 Grafik Hubungan Jenis Tanah Dan Twist \& Sway

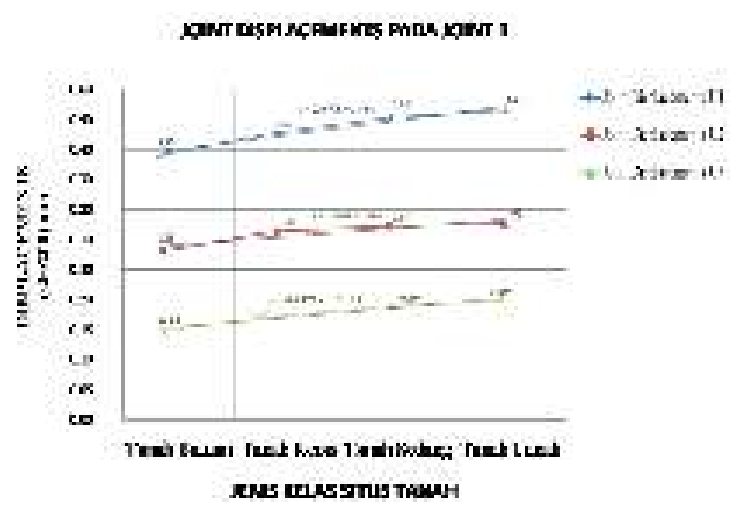

Gambar 15 Grafik Hubungan Jenis Tanah Dan Displacement

\section{KESIMPULAN}

Dari hasil analisa di atas didapat kesimpulan sebagai berikut:

1. Pengaruh beban gempa terhadap nilai Twist, Sway, dan Displacement yang terjadi pada struktur tower BTS tidak melebihi syarat yang di tentukan dimana nilai Twis dan Sway tidak melebihi $\mathbf{0 . 5}^{\mathbf{0}}$ dan untuk nilai Displacement tidak melebihi H/200 (30000/200 = $\mathbf{1 5 0} \mathbf{~ m m})$.

2. Pengaruh beban gempa dengan beberapa situs kelas tanah yang berupa tanah batuan, tanah keras, tanah sedang dan tanah lunak didapat nilai twist \& sway sebagai berikut :

a. Semakin lunak kondisi tanah maka terjadi peningkatan nilai Twist pada struktur tower dimana nilai Twis tertinggi terjadi pada jenis tanah lunak pada arah Y sebesar $0.015^{\circ}$.

b. Semakin lunak kondisi tanah maka terjadi peningkatan nilai Sway pada struktur tower dimana nilai Sway tertinggi terjadi pada jenis tanah lunak pada arah Y sebesar $0.227^{0}$.

3. Pengaruh Displacement yang terjadi akibat beban gempa dimana :

a. Pada arah $\mathrm{x}$ terjadi peningkatan nilai Displacement dari jenis tanah batuan ke jenis tanah lunak dimana nilai Displacement tertinggi terjadi pada 
jenis tanah lunak sebesar $5.31 \mathrm{~mm}$ $<\mathrm{H} / 200(30000 / 200=150 \mathrm{~mm})$.

b. Pada arah y terjadi peningkatan nilai Displacement dari jenis tanah batuan ke jenis tanah lunak dimana nilai Displacement tertinggi terjadi pada jenis tanah lunak sebesar $1.62 \mathrm{~mm}$ $<\mathrm{H} / 200(30000 / 200=150 \mathrm{~mm})$.

c. Pada arah z terjadi peningkatan nilai Displacement dari jenis tanah batuan ke jenis tanah lunak dimana nilai Displacement tertinggi terjadi pada jenis tanah lunak sebesar $0.20 \mathrm{~mm}<$ $\mathrm{H} / 200(30000 / 200=150 \mathrm{~mm})$.

4. Hasil dari perhitungan pengaruh beban gempa terhadap nilai twist, sway (point 2) maupun displacement (point 3) yang terjadi pada struktur tower BTS masih dibawah/tidak melebihi syarat nilai yang ditentukan. Nilai puntiran, goyangan maupun perpindahan yang diakibatkan beban gempa tersebut dengan kondisonal berbagai jenis tanah dikabupaten jember, masih AMAN dimana gaya - gaya yang ditimbulkan tidak berpengaruh pada struktur Tower BTS maupun antena yang terpasang.

\section{REFERENSI}

[1] ANSI/TIA/EIA. 1996, Structural Standards

for Steel Antenna Tower and Antenna Supporting Structure.

U.S.A.

[2] American Institute of Steel Construction

(AISC). (2010), Specification for structural steel buildings, Chicago.

[3] ASTM. 2014. Annual Book of ASTM

Standards. Vol. 05.06. American Society for Testing and Materials: West Conshohocken, PA.

[4] Badan Standarisasi Nasional. 2012. Tata
Cara Perencanaan Ketahanan Gempa Untuk Bangunan Gedung (SNI 03-1726-2012). Jakarta.

[5] Gunawan, Rudi. 1987, Tabel Profil Konstruksi Baja, Kanisius, Jakarta. Pusat Penelitian dan Pengembangan Permukiman - Kementerian Pekerjaan Umum. Aplikasi Desain Spectra Indonesia, PPMB-ITB 